\title{
Molecular Characterization of Trichophyton Verrucosum Strains Isolated From Cattle by PCR-RFLP
}

\author{
Osman Yaşar TEL1, Ayfer GÜLLÜ YÜCETEPE1*, Oktay KESKİN1', Sevil ERDENLİĞ GÜRBİLEK¹ \\ ${ }^{1}$ Harran University, Faculty of Veterinary Medicine, Department of Microbiology, 63000, Şanluurfa, Turkey
}

\begin{abstract}
Dermatophytes infect tissues containing keratin in humans and animals, causing dermatophytosis infection. Trichophyton verrucosum is the most common agent of bovine dermatophytosis cases. Trichophytosis causes big economic lossess throughout the world and also threatens human health by being a zoonosis. T. verrucosum is usually isolated from cattle. Cattle are the natural reservoirs of this agent. The aim of this study is to isolate disease-causing dermatophytes in cattle and to carry out molecular separation of Internal Transcribed Spacer (ITS) regions of the isolated T. verrucosum strains by PCR- Restriction Fragment Lenght Polymorphism (PCRRFLP). For this purpose, 90 samples were taken from the cattle with dermatophytosis for cultural examination. As a result of the culture of these samples, $35(38.8 \%)$ T. verrucosum were isolated and identified. DNA isolation of these strains was made and amplification of ITS regions was performed. It was only one RFLP profile was found according to the results of RFLP analysis of T. verrucosum strains using MvaI and HinfI enzymes. At the end of study, it was founded that the isolated T. verrucosum strains showed a single profile by PCR-RFLP analysis and PCR-RFLP was a useful tool for the molecular characterization of the strains. İt was also concluded that PCRRFLPs of strains from different regions or even from different countries might be necessary in order to detect different profiles of the tested samples.
\end{abstract}

Keywords: Cattle, Dermatophytosis, PCR-RFLP, Trichophyton verrucosum.

\author{
$* * *$ \\ Sığırlardan İzole Edilen Trichophyton Verrucosum Suşlarının PCR -RFLP ile Moleküler \\ Karakterizasyonu
}

ÖZ

Dermatofitler, insan ve hayvanlarda keratin içeren dokuları infekte ederek dermatofit infeksiyonuna neden olmaktadırlar. Trichophyton verrucosum sığır dermatofitozis olgularının en yaygın etkenidir. Trichophytosis, bütün dünyada hayvancilık sektöründe önemli ekonomik kayıplara neden olması yanında zoonoz olmasiyla da insan sağlığını tehdit etmektedir. Sığırlardan genellikle T. verrucosum izole edilmektedir. Sığırlar bu etkenin doğal rezervuarıdırlar. Bu çalışmanın amacı, sığırlarda hastalığa neden olan dermatofitlerinin izolasyonu ve izole edilen T. verrucosum suşlarının Internal Transcribed Spacer (ITS) bölgelerinin PCR-RFLP ile moleküler ayrımının yapılmasıdır. Bu amaçla dermatofitozisli sığırlardan 90 adet örnek alınarak kültürleri yapıldı. Bu örneklerin kültürü sonucunda $35(\% 38,8)$ adet T. verrucosum izole ve identifiye edildi. Bu suşların DNA izolasyonu gerçekleştirilerek ITS bölgelerin amplifikasyonu gerçekleştirildi. T. verrucosum suşlarının MvaI ve HinfI enzimleri kullanılarak yapılan Restriction Fragment Lenght Polymorphism (RFLP) analizleri sonucunda bir adet RFLP profiline rastlandi. Sonuç olarak, izole edilen T. verrucosum suşlarının PCR-RFLP sonucunda tek bir profile sahip olduğu, farklı profil örneklerinin saptanması için farklı bölgelerden hatta farklı ülkelerden suşların PCR-RFLP’lerinin yapılması gerektiği kanısına varıldı.

Anahtar Kelimeler: Dermatofitosis, PCR-RFLP, Sı̆̆ır, Trichophyton verrucosum

To cite this article: Tel O.Y. Güllü Yücetepe A. Keskin O. Erdenliğ Gürbilek. S. Molecular Characterization of Trichophyton Verrucosum Strains Isolated From Cattle by PCR-RFLP. Kocatepe Vet J. (2021) 14(1):51-56

Submission: 24.07.2020 Accepted: 01.02.2021 Published Online: 18.02.2021

ORCID ID; OYT: 0000-0001-7848-3899, AGY:0000-0002-9842-3305, OK: 0000-0002-5977-7872, SEG: 0000-0002-0377-2650

*Corresponding author e-mail: ayfergullu@harran.edu.tr 


\section{GİRİş}

Dermatofitozis pet ve çiftlik hayvanlarında en s1k görülen mantar infeksiyonudur. Günümüzde hayvan ve insanlarda enfeksiyona yol açan dermatofitler; Microsporum, Trichophyton ve Epidermophyton olarak 3 cins içinde sinıflandırılırlar. Evcil hayvanlardan çok farklı türde dermatofitler izole edilmesine rağmen, yalnızca Microsporum ve Trichophyton cinsine ait birkaç zoofilik tür (M. canis, T. verrucosum, $T$. mentagrophytes, $T$. equinum, ve $M$. sypseum) infeksiyonların çoğundan sorumludur. Sığırlarda hastalık vakalarının çoğundan sorumlu olan en yaygın tür, Trichophyton verrucosum' dur. Zoonotik öneme sahip $T$. verrucosum türlerinin alt tiplerini belirlemek, hastalığın tedavisi ile yayılmasını önleme ve kontrol altına almada oldukça yararlıdır (Arda, 1980).

Mantar türlerinin alt tiplerini belirlemek için çeşitli yöntemlerden yararlanılmaktadır. Fakat halen altın standart denilecek bir yöntem belirlenememiştir. Mitokondrial DNA'daki kesim bölgesi polimorfizmi (Restriction Fragment Length Polymorphism-RFLP), DNA üzerinde ribozomal RNA'nın (rRNA) kodlandiğ1 bölgede (rDNA) bulunan internal transcribed spacer (ITS) bölgelerinin sekanslanmas1 (Jackson ve ark. 1999, Mochizuki ve ark. 1999) ve polymerase chain reaction (PCR) [RAPD (random amplification of polymorphic DNA), AP-PCR (arbitrarily primed) ve PCR fingerprinting], tür ve suşların ayırt edilmesinde önemli yararlar sağlamıştır (Kac 2000, Thomas ve Xu, 2002). PCR-RFLP T. verrucosum'un intraspesifik polimorfizminin ortaya çıkarılmasında değerli bir araç olduğu düşünülmektedir (Mirzahoseini ve ark. 2009). HinfI ve MvaI enzimleriyle ITS I PCR ürünlerini kestikleri çalışmada 2 adet $T$. verrucosum profili elde etmişlerdir. Tip II profilin en yaygin profil olduğunu belirtmişlerdir (Neji ve ark. 2016).

$\mathrm{Bu}$ çalışmanın amac1, sığırlarda hastalığa neden olan T. verrucosum izolasyonu ve izole edilen $T$. verrucosum suşlarının Internal Transcribed Spacer (ITS) bölgelerinin PCR-RFLP ile moleküler ayrımının yapilmasidir.

\section{MATERYAL ve METOT}

$\mathrm{Bu}$ çalışmada, Şanlıurfa ilinin farklı ilçe ve merkez ilçelerinden Mikrobiyoloji Anabilim Dalına yapılan başvurular doğrultusunda teşhis amacıyla örnekler topland1. Örnekler, genellikle aile tipi küçük işletmelerden farklı cinsiyet ve yaşlardaki hayvanlardan alındı (Tablo 1). Bu amaçla klinik olarak dermatofitoz şüpheli hayvanlardan $T$. verucosum yönünden incelenmek üzere toplam 90 sı̆̆ır orijinli örnek (deri döküntüleri ve kıl) alındı. Örnek alınmadan önce derideki büyüklüğü, lezyonların yeri, şekli, yayılma durumu gibi önemli noktalara dikkat edilerek, lezyon ve çevresi \%70'lik alkol ile iyice silindi ve deri döküntüleri steril bistüri ile alındı, kıllar ise steril bir pensle çekilerek steril materyal kaplarına alındı ve en kısa sürede laboratuvara ulaştırıldı

\section{Kültür}

T. verrucosum üretilmesi amaciyla Sabouraud Glucose Agar (SGA) (Merck, Darmstadt, Germany)'a thiamine (4 mg/ml), inositol $(100 \mathrm{mg} / \mathrm{ml})$, cycloheximide $(0,5$ $\mathrm{mg} / \mathrm{ml})$ ve chloramphenicol $(0,1 \mathrm{mg} / \mathrm{ml})$ kat1larak kullanıld1. Laboratuvara getirilen örneklerden SGA'a ekimler yapıld1. Besiyerleri, $37^{\circ} \mathrm{C}^{\prime}$ lik etüvde 3-4 günde bir oluşan üremeler kontrol edilerek dört hafta süreyle inkübasyona birakildı. Laktofenol pamuk mavisi boyası kullanılarak kolonilerden bir kısım alınarak lam-lamel arası preparatlar hazırlandi. İnkübasyon sonunda kolonilerin üreme hızları, yüzey renkleri, morfolojileri, tabandaki pigmentleri ve mikroskobik incelemede konidiyumların varlığ1, hiflerin yapıs1 göz önüne alınarak $T$. verrucosum yönünde identifikasyonları gerçekleştirildi (Larone, 2002). Ayrica Trichophyton şüpheli kolonilerin Trichophyton agara subkültürleri yapılarak makroskopik ve mikroskobik özellikleri incelendi.

\section{Moleküler Metodlar}

\section{DNA Ekstraksiyonu}

Liu ve ark. (2000)'nın bildirdiği DNA ekstraksiyon yöntemi kullanıldı. Bu yönteme göre steril öze ile az miktarda miselyum $500 \mu l^{\prime}$ lik lizis solüsyonu $(400 \mathrm{mM}$ Tris-HCl [pH 8,0], 60 mM EDTA [pH 8,0], $150 \mathrm{mM}$ $\mathrm{NaCl}, \% 1 \mathrm{SDS}$ ) içeren bir ependorf tüpüne alınarak, 10 dakika oda sıcaklığında inkübe edildi. Bu tüpe 150 $\mu l$ potasyum asetat solüsyonu eklendikten sonra, tüp hafifçe vortekslendikten sonra, 14.000 devirde $1 \mathrm{dk}$. santrifüje edildi. Süpernatant başka bir ependorf tüpüne aktarılarak, tekrar yukarıdaki şartlarda santrifüje edildi. Elde edilen süpernatant nükleaz-ari bir ependorf tüpüne aktarlarak üzerine eşit hacimde izopropil alkol eklendi. Tüp hafifçe ters yüz edilerek karıştırıldı ve 12.000 devirde 2 dakika santrifüj edildi. Süpernatant pelet kaybedilmeden dikkatli bir şekilde uzaklaştırıldı. Elde edilen DNA peleti, $300 \mu \mathrm{l} \% 70^{\prime}$ lik etanol ile vortekslenip santrifüje edilerek y1kandi. Pelet 10.000 devirde 1 dakika santrifüje edildikten sonra, süpernatant atılarak ve DNA peleti oda sicaklığında tutularak kurutuldu. DNA peleti $50 \mu \mathrm{L}$ nükleazsız su içerisinde çözüldü

\section{ITS Bölgesinin PCR İşlemi ile Çoğaltılması}

PCR reaksiyon karışımı; $5 \mu$ l template DNA, 1.5-3 $\mathrm{mM} \mathrm{MgCl} 2,0.8 \mathrm{mM}$ dNTP karışımı, $0.7 \mu \mathrm{M}$ primerler (ITS1, ITS4), 1/10 reaksiyon buffer, $1.25 \mathrm{U}$ Taq DNA polimeraz ve son hacmi $50 \mu$ l olacak şekilde steril distile sudan oluştu. PCR inkubasyon, sıcaklık ve süreleri sırasıly, $94^{\circ} \mathrm{C}$ 'de 3 dakikalık ilk denatürasyon, $94^{\circ} \mathrm{C}$ 'de 1 dakikalık denatürasyon, $60^{\circ} \mathrm{C}$ 'de 1 dakika primer bağlanması, $72^{\circ} \mathrm{C}$ 'de 1 dakikalık ekstensiyonu içeren 35 siklustan oluştu (Hsiao ve ark. 2005). İzole edilen T. verrucosum suşlarının ITS bölgesini çoğaltmak için PCR işleminde 
kullanılmak üzere White ve ark. (1990) tarafindan oldukça duyarlı ve özgün olduğu bildirilen mantarlara özgü universal primerler kullanıldı.
Forward primer olarak:
TCCGTAGGTGAACCTGCGG-3’)
Reverse primer olarak. ITS 4 (5'
TCCTCCGCT'TAT'TGA TATGC-3’).

\section{PCR Ürünlerinin Görüntülenmesi ve Pürifikasyonu}

Amplifikasyon ürünleri \%2 agaroz jel elektroforezi ile ayrımlanarak UV ışı̆̆ı altında konrol edildi.

\section{PCR-RFLP}

$\mathrm{Bu}$ amaçla HinfI ve MvaI (Thermo Scientific, USA) enzimleriyle PCR ürünleri kesildi. Bütün işlemler üretici firmanın protokolleri doğrultusunda yapıldı. Reaksiyon karışımı

10 ul PCR reaksiyon ürünü ( $0.1-0.5 \mu \mathrm{g}$ of DNA)

17 ul nukleaz içermeyen su

2 ul 10x buffer

2 ul enzim (HinfI veya MvaI) 'den oluştu.
Bu karıșım hafifçe birkaç dakika karıştırıldıktan sonra $37^{\circ} \mathrm{C}$ 'de 1-16 saat inkübasyona birakıld1.

\section{ITS Bölgesinin Sekanslanması}

PCR ürünleri Big Dye Cycle Sequencing kit v 3.1 kullanilarak ABI PRISM 3130XL automated sequencer (Applied Biosystems) ile çift taraflı olarak sekanslandi. Elde edilen sekans bilgileri Bioedit Alignment Sequence Editor ile incelendi (Hall, 1999). Tespit edilen sekanslar, web tabanlı BLAST programı (http://blast.ncbi.nlm.nih.gov) kullanilarak GenBank'tan elde edilen benzer sekanslarla karşılaştırıldı.

\section{BULGULAR}

Toplam 90 sığıra ait örneklerin kültür ile incelenmesi sonucunda, $35(\% 38,8)$ örnekte makroskobik ve mikroskobik olarak $T$. verucosum olarak identifiye edilen üremeler görüldü (Tablo 1).

Tablo 1. İncelenen örneklerin yaş gruplarına ve bölgelere göre dağılımı.

Table 1. Distribution of the studied samples by age groups and regions.

\begin{tabular}{|c|c|c|c|c|c|c|c|c|c|}
\hline \multirow{3}{*}{$\begin{array}{l}\text { Örnek } \\
\text { alınan } \\
\text { bölge }\end{array}$} & \multirow{3}{*}{$\begin{array}{l}\text { Örnek } \\
\text { alınan } \\
\text { işletme } \\
\text { sayısı }\end{array}$} & \multicolumn{6}{|c|}{ Yaş grupları } & \multicolumn{2}{|c|}{ Toplam } \\
\hline & & \multicolumn{2}{|c|}{$0-6$ ay } & \multicolumn{2}{|c|}{6 ay- 1 yaş } & \multicolumn{2}{|c|}{1 yaş ve üzeri } & \multirow{2}{*}{$\begin{array}{l}\text { Alınan } \\
\text { örnek } \\
\text { sayısı }\end{array}$} & \multirow{2}{*}{$\begin{array}{l}\text { Pozitif } \\
\text { örnek } \\
\text { sayısı }\end{array}$} \\
\hline & & $\begin{array}{l}\text { Alınan } \\
\text { Örnek } \\
\text { Sayısı }\end{array}$ & $\begin{array}{l}\text { Pozitif } \\
\text { Bulan } \\
\text { Örnek } \\
\text { Sayısı }\end{array}$ & $\begin{array}{l}\text { Alınan } \\
\text { Örnek } \\
\text { Sayısı }\end{array}$ & $\begin{array}{l}\text { Pozitif } \\
\text { Bulan } \\
\text { Örnek } \\
\text { Sayısı }\end{array}$ & $\begin{array}{l}\text { Alınan } \\
\text { Örnek } \\
\text { Sayısı }\end{array}$ & $\begin{array}{l}\text { Pozitif } \\
\text { Bulan } \\
\text { Örnek } \\
\text { Sayısı }\end{array}$ & & \\
\hline Suruç & 2 & 10 & 8 & 10 & 9 & - & - & 20 & 17 \\
\hline Bozova & 1 & & & 2 & 1 & 12 & 1 & 14 & 2 \\
\hline Haliliye & 4 & 19 & 4 & 4 & 1 & - & - & 23 & 5 \\
\hline Eyyübiye & 4 & 11 & 4 & 8 & 5 & 14 & 2 & 33 & 11 \\
\hline Toplam & 11 & 40 & 16 & 24 & 16 & 26 & 3 & 90 & 35 \\
\hline
\end{tabular}

(Şekil 1). PCR ürünlerinin sekanslanması sonucunda

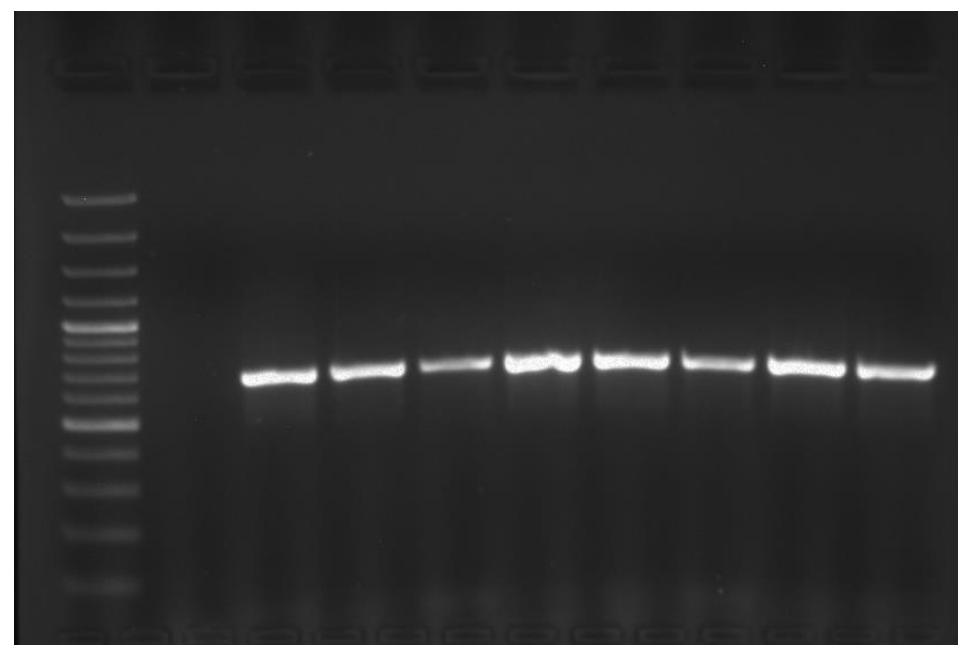

Şekil 1: T. verrucosum suşlarının PCR ürünlerinin agaroz jel görüntüsü. M: marker T. verrucosum suşları, 1,2,3,4,5,6,7,8 (622 bp)

Figure 1: Agarose gel view of PCR products of T. verrucosum strains. M: marker T. verrucosum strains, 1,2,3,4,5,6,7,8 $(622$ 
PCR ürünlerinin RFLP analizi sonucunda HinfI (200159-145 bp) ve MvaI (518-140 bp) enzimi kullanılarak yapilan kesimlerde ise tek bir profil görüldü. (Şekil 2-3).

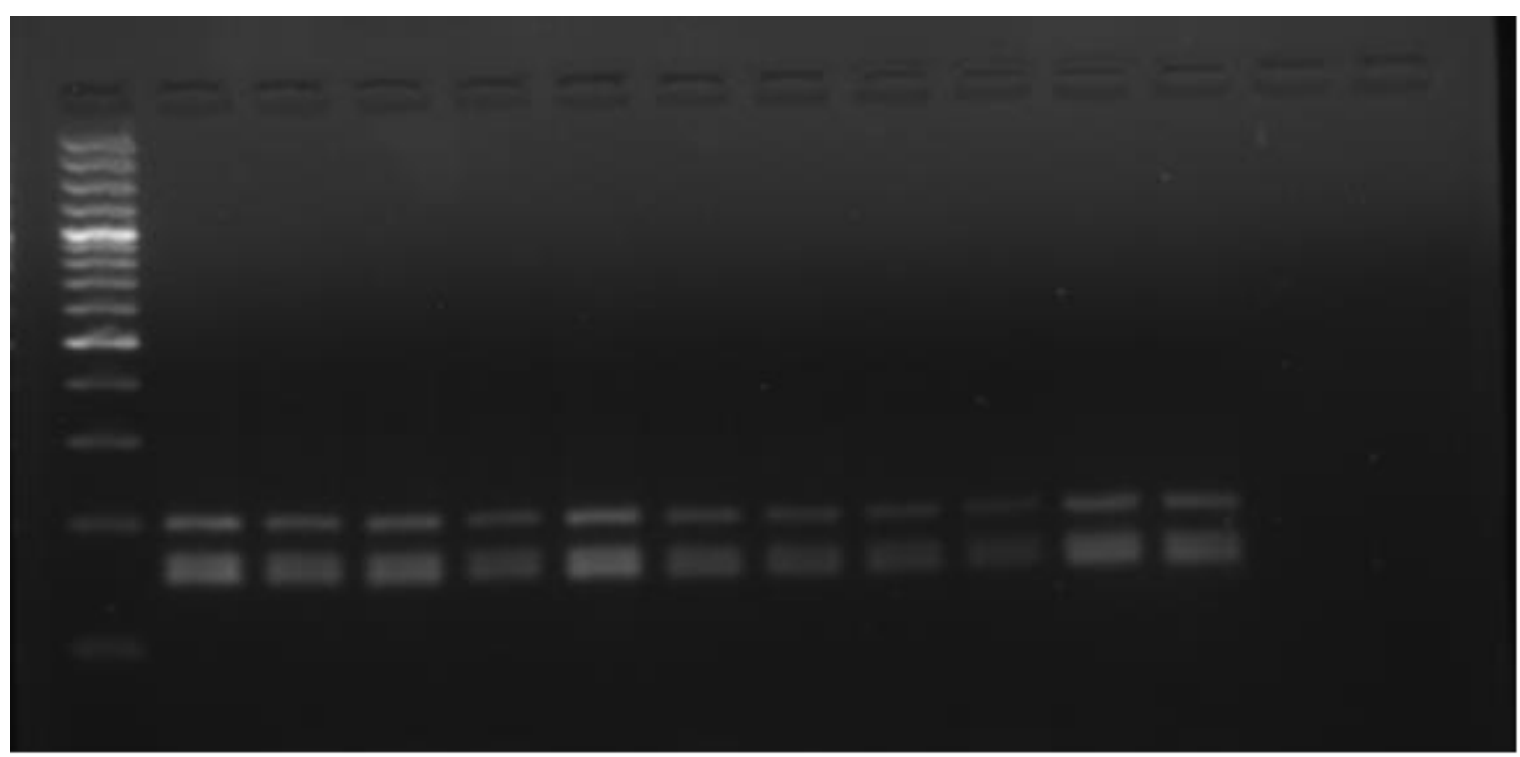

Şekil 2: HinfI enzimi kesim sonrası agaroz jel elektroforez görüntüsü. M: marker T. verrucosum suşlarının RFLP profilleri 1,2,3,4,5,6,7,8,9,10,11 (200-159-145 bp)

Figure 2: HinfI enzyme agarose gel electrophoresis image after cutting. M: marker RFLP profiles of T. verrucosum strains $1,2,3,4,5,6,7,8,9,10,11(200-159-145 \mathrm{bp})$

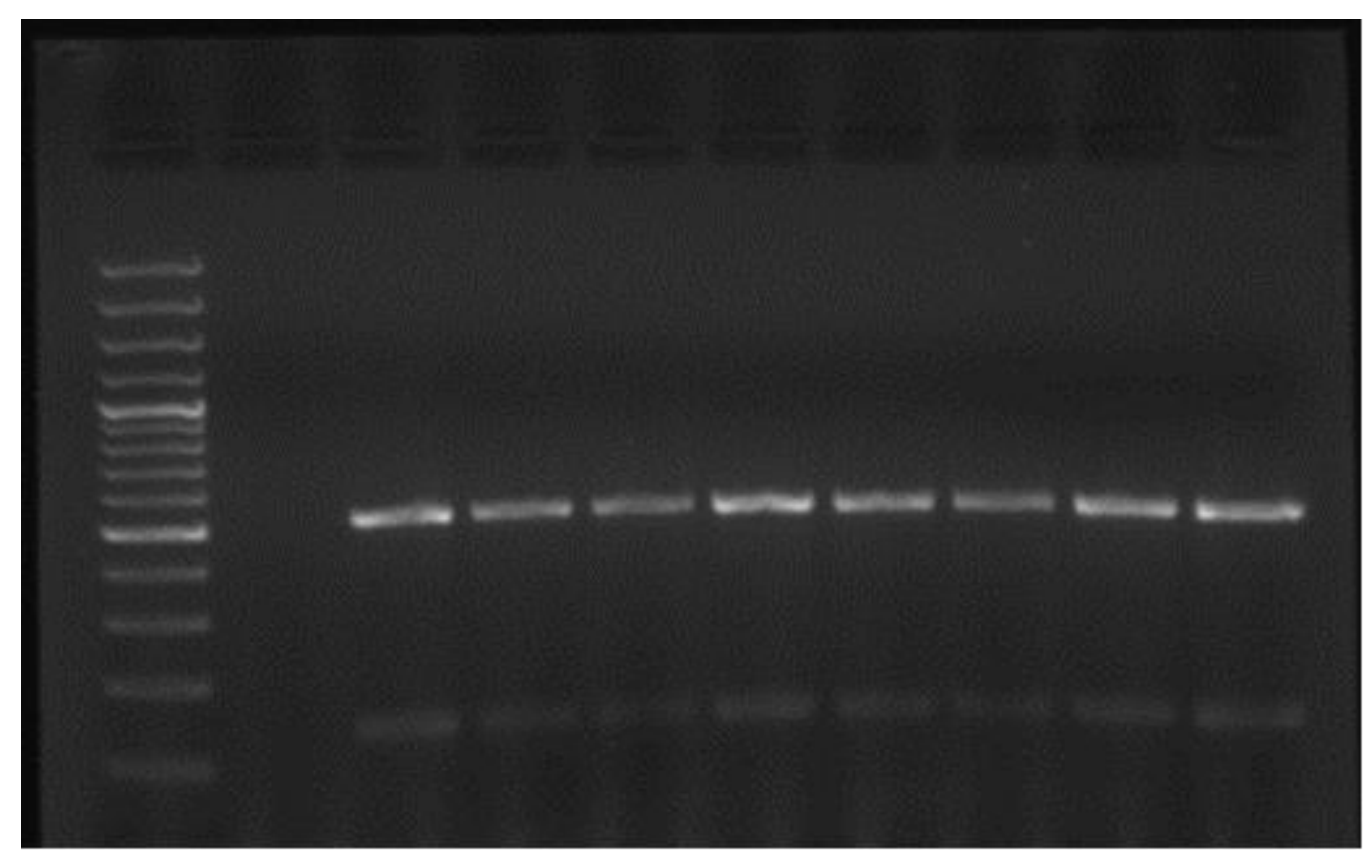

Şekil 3: MvaI enzimi kesim sonrası agaroz jel elektroforez görüntüsü. M: marker T. verrucosum suşlarının RFLP profilleri 1,2,3,4,5,6,7,8 (518-140 bp)

Figure 3: Agarose gel electrophoresis image after cutting MvaI enzyme. M: marker RFLP profiles of T. verrucosum strains $1,2,3,4,5,6,7,8(518-140 \mathrm{bp})$ 


\section{TARTIŞMA}

Sığırlardan genellikle $T$. verrucosum izole edilmektedir. Sığırlardan $T$. verrucosum dışında $M$. gypseum, $T$. mentagrophytes, $T$. rubrum ve $T$. simii izole edildiği bildirilmiștir (Mitra ve ark. 1998). Bu çalıșmada dermatofitoz şüpheli 90 sığırın $35(\% 38,8)$ 'inden $T$. verrucosum izole edilmiştir. İran'da Khosravi ve Mahmoudi (2003) deri lezyonu olan sığırların $\% 85$ 'inden T. verrucosum, \%15'inden T. mentagrophytes izole etmişlerdir. Abou-Eisha ve ark. (2008) yaptıklar1 çalışmada kültürel olarak pozitif olan dermatofit izolatlarından, sığırların 54 (\%75)'ünden T. verrucosum izole etmişlerdir. Yıldırım ve ark (2010)'ları Kırıkkale bölgesinde yaptıkları çalışmada klinik olarak dermatofitoz lezyonları gösteren 50 ineğin \%44'ünden $T$. verrucosum izole ettiklerini belirtmişlerdir. Aghamirian ve Ghiasian (2011) yaptıkları çalışmada 380 sığırın 352 (\%92,6)'sinden, Papini ve ark. (2009), 294 sığırdan \%87,7 oranında T. verrucosum izole etiklerini bildirmişlerdir. AbdElmegeed ve ark. (2020)'nin Misır'da yaptiklar1 çalışmada, T. verrucosum'un $(\% 25,6)$ oranında en sık saptanan dermatofit türü olduğunu bildirilmişlerdir. Bizim çalışmamızda izolasyon oranı Yıldııım ve ark (2010) 'nın bulgularına benzer görülürken AbdElmegeed ve ark. (2020)'nın bulgularından yüksek, diğer çalışmalardan ise düşük olarak bulunmuştur. Bunun bölgesel farkliliklardan kaynaklandiğ1 düşünülmekle beraber en sik izole edilen etkenin $T$. verrucosum olması diğer çalışmalara benzer olarak görülmüştür.

Bu çalıșmada 35 suşun PCR ürünlerinin RFLP analizi sonucunda HinfI (200-159-145 bp) ve MvaI (518-140 bp) enzimi ile kesim sonrasinda tek bir profil görüldü. Neji ve ark. (2016), çalışmalarında HinfI enzimiyle 3 profil, MvaI enzimiyle 2 profil elde etmişlerdir. HinfI ile A [372-159-145 bp] (79.4\%), B [372-304-159-145 bp] $(14.7 \%)$ ve C [306-200-164 bp] (5.9\%), MvaI enzimi ile 2 (I [406-125-89-50 bp] (94.1\%) ve (II [518$140 \mathrm{bp}](5.9 \%)$ profil elde etmişlerdir. Ancak bu profillerden sadece bir tanesinin çok yaygin olduğunu bildirmişlerdir. Jha ve ark (2012), 11 T. verrucosum suşunu HaeIII enzimini kullanarak PCR-RFLP ile inceledikleri çalışmada tek profil elde etmişlerdir. Mirzahoseini ve ark (2009), PCR-RFLP kullanarak dermatofitlerin hızlı identifikasyonlarını amaçladıkları çalışmada 6 dermatofit türünü (T. mentagrophytes, $T$. rubrum, T. verrucosum, T. tonsurans, Microsporum canis ve Epidermophyton floccosum) MvaI, HinfI and HaeIII enzimleri ile kesimlerini gerçekleştirmişlerdir. Kesim sonucunda tek profil elde ederek PCR-RFLP'nin özellikle tür ya da cins düzeyinde identifikasyon için yararlı bir araç olduğunu belirtmişlerdir. ITS bölgesinin MvaI enzimi kullanılarak kesiminin yapıldığı başka bir çalışmada 2 RFLP profili elde edilmiştir. Birinci patern'de iki fragmentten oluşurken
(380 bp-220 bp) ikinci profil kesilmeden tek fragmentten (600 bp) oluşmuştur (Dalis ve ark. 2018). Bu çalışmada tek profil elde edilmesi Jha ve ark (2012) ile Mirzahoseini ve ark (2009)'nun bulgularına benzer görülürken diğer çalışmalardan faklı olarak görülmüştür. Bunun nedeninin örneklemenin küçük bir alanda (Şanlıurfa) yapılmasından kaynaklandığı düşünülmektedir.

\section{SONUÇ}

Sonuç olarak, izole edilen suşların tek bir profile sahip olduğu ve $T$. verrucosum suşlarının tiplendirilmesinde ITS-RFLP'nin kullanılabilir ve tekrarlanabilir bir test olduğu sonucuna varıldı. Daha sonraki çalışmalarda daha geniş bir alandan örnek alınarak PCR-RFLP tiplendirilmesinin yapilmasının yararlı olacağı sonucuna varıld 1

Proje Destek Bilgileri: $\mathrm{Bu}$ çalışma, Harran Üniversitesi Bilimsel Araştırma Projeleri Koordinatörlüğü (HÜBAK) tarafindan 17057 proje numarası ile desteklenmiștir.

Etik Kurul Bilgileri: Bu çalısma "Hayvan Deneyleri Etik Kurullarının Çalışma Usul ve Esaslarına Dair Yönetmelik" Madde 8 (k) gereği HADYEK iznine tabi değildir.

Çıkar Çatışması: Yazarlar, çıkar çatışması olmadığını beyan eder.

\section{KAYNAKLAR}

Abd-Elmegeed M, El-Mekkawi MF, El-Diasty EM, Fawzi EM. Dermatophytosis among Ruminants in Egypt: The Infection Rate, Identification and Comparison between Microscopic, Cultural and Molecular Methods. Zagazig Veterinary Journal. 2020; 48(2): 116-127.

Abou-Eisha A, Sobih M, Fadel H, Elmahallawy H. Dermatophytes in animals and their zoonotic importance in Suez canal area. Suez Canal Vet Med J. 2008; 13(2): 625-642.

Aghamirian MR, Ghiasian SAJM. Dermatophytes as a cause of epizoonoses in dairy cattle and humans in Iran. Epidemiological and clinical aspects. 2011; 54(4): e52-e6.

Arda M. Mikoloji. Ankara Üniversitesi Basımevi. Ankara. 1980 Pp: 15-23.

Dalis JS, Kazeem HM, Kwaga JK, Kwanashie CN, Yakubu B, Owolodun OA, Jambol AR. Molecular characterization of dermatophytes isolated from cattle in Plateau State, Nigeria. Vet microbiol. 2018; 219: 212-218.

Hall TA. BioEdit: A user-friendly biological sequence alignment editor and analysis program for Windows 95/98/NT. Nucleic acids symposium series 1999; 41: 95-98.

Hsiao CR, Huang L, Bouchara JP, Barton R, Li HC, Chang TC. Identification of medically important molds by an oligonucleotide array. J Clin Microbiol. 2005; 43: 37603768. 
Jackson CJ, Barton, RC, Evans EG. Species identification and strain differantiation of dermatophyte fungi by analysis of ribosomal-DNA intergenic spacer regions. J. Clin.

Microbiol. 1999; 31: 931-936.

Jha BK, Murthy SM, Devi NL. Molecular identification of dermatophytosis by polymerase chain reaction (PCR) and detection of source of infection by restricted fragment length polymorphism (RFLP). Journal of College of Medical Sciences. Nepal. 2012; 8(4): 7-15.

Kac G. Molecular approaches to the study of dermatophytes. Med. Mycol. 2000; 38: 329-336.

Khosravi AR, Mahmoudi M. Dermatophytes isolated from domestic animals in Iran. Mycoses. 2003; 46: 222-225.

Larone, D.H. Medically Important Fungi, In: A Guide to Identification, 4nd Ed., Washington, ASM press. 2002.

Liu D, Coloe S, Baird R, Pedersen J. Rapid mini-preparation of fungal DNA for PCR. Journal of clinical microbiology. 2000; 38(1): 471-471.

Mirzahoseini H, Omidinia E, Shams-Ghahfarokhi M, Sadeghi G, Razzaghi-Abyaneh M. Application of PCR-RFLP to rapid identification of the main pathogenic dermatophytes from clinical specimens. Iranian Journal of Public Health. 2009; 18-24.

Mitra SK, Sikdar A, Das P. Dermatophytes isolated from selected ruminants in India. Mycopathologia. 1998; 142: 13-16.

Mochizuki T, Kawasaki M, Ishizaki H, Makimura K. Identification of several clinical isolates of dermatophytes based on the nucleotide sequence of internal transcribed spacer 1 (ITS 1) in nuclear ribosomal DNA. J. Derm. 1999; 26: 276-281.

Neji S, Trabelsi H, Hadrich I, Cheikhrouhou F, Sellami H, Makni F, Ayadi A. Molecular characterization of strains of the Trichophyton verrucosum complex from Tunisia. Medical Mycology. 2016; 1-7.

Papini R, Nardoni S, Fanelli A, Mancianti F. High Infection Rate of Trichophyton verrucosum in Calves from Central Italy. Zoonoses Public Health. 2009; 56: 59-64.

Thomas GM, Xu J. Moleculer methods to identify pathogenic fungi In: Pathogenic Fungi in Humans and Animals. Ed.: D.H. Howard, Marcel Dekker, NY. 2002 p: 677-702

Yildirim M, Cinar M, Ocal N, Yagci BB, Askar S. Prevalence of Clinical Dermatophytosis and Oxidative Stress in Cattle. Journal of Animal and Veterinary Advance. 2010; 9(14): 1978-1982.

White T, Burns T, Lee S, Taylor J. Amplification and direct sequencing of fungal ribosomal RNA genes for phylogenetics In: PCR protocols, A guide to methods and applications. Ed.: M. A. Innis, D. H. Gelfand, J. J. Sninsky, and T. J. White. Academic Press, Inc., San Diego, Calif. 1990 p. 315-322 